\title{
Should We Legalise Recreational Drugs? An Ethical Question for Animals and Humans
}

\author{
Ian C. Shaw
}

Published online: 18 July 2013

(c) Springer International Publishing Switzerland 2013

Recreational drugs have been with us since time immemorial—opium was probably cultured by prehistoric people in the $6^{\text {th }}$ millennium $\mathrm{BC}$ and it has been suggested that some otherwise unexplainable fantastical cave drawings reflect recreational drug use [1]. Much more recently, Sir Arthur Conan Doyle stimulated his imagination with cocaine and perhaps opium [2] which likely led to his opium-addicted alter-ego Sherlock Holmes' exploits; Pete Townshend, of The Who, was probably high on lysergic acid diethylamide (LSD), cocaine or cannabinoids when he composed many of his most celebrated works [3]; and sufferers of debilitating and painful diseases, like multiple sclerosis, find solace in an illegal smoke of cannabis [4] in some countries, whereas they might be able to use cannabis legally in other jurisdictions (e.g. California, USA [5]). But, perhaps more importantly, millions of young people throughout the world party on Saturday night under the influence of a new generation of psychoactive drugs including, synthetic cannabinoids (e.g. JHW-018), BZP and methamphetamine.

The question is should we legalise the recreational use of these drugs? Legalising them would mean that their safety would be assessed and the cost of policing and prosecuting illicit drug use would be cut. The Netherlands was the first country to legalise a recreational drug, cannabis, with an arguably successful outcome. But, should we go further? Should such drugs and their synthetic derivatives become legal products marketed by a new pharmaceuticals industry?

\footnotetext{
I. C. Shaw $(\bowtie)$

University of Canterbury, Private Bag 4800,

Christchurch, New Zealand

e-mail: ian.shaw@canterbury.ac.nz
}

The New Zealand government has decided to legalise psychoactive recreational drugs and has embarked upon the process of setting the requirements for safety evaluation. ${ }^{1}$ There is significant controversy about whether it is ethical to use animals to test drugs with an, at best, dubious benefit. This debate is important because it addresses the question when is the use of animals in drug testing ethically acceptable? Indeed, it was conceivable that this debate might derail the New Zealand government's Psychoactive Substances Bill (2013) [6], and, as a result, the Parliamentary Select Committee has refused to consider submissions on the ethics of animal use in testing recreational drugs. The rationale behind this decision is that ethics committees will decide whether the use of animals to test recreational drugs is appropriate or not. But it is likely that recreational drug manufacturers will hail from parts of the world where ethics are far from most people's minds especially when there a significant financial benefit that depends on animal use.

Toxicologists have been through a painful and arduous process (mainly in the 1980s) to understand the ethics of animal use in their work. It took significant action by extremist antivivisectionists and reasonable protesters alike to precipitate a rethink of animal use. Now most toxicologists take the use of animals in their work very seriously and will not use animals unless the outcome of their work is important. Defining 'important' is difficult, but in the context of drug safety evaluation this would be that the resulting drug has a benefit that balances the sacrifice of animals as part of its development process.

\footnotetext{
1 The Psychoactive Substances Bill was passed by the New Zealand House of Representatives on 12th July 2013 and awaits Assent of the Governor General before it becomes law.
} 
In the decades since the 1970s there has been vigorous debate amongst toxicologists and society as a whole about whether animals should be used in experiments and particularly in safety testing of products intended for use on humans and animals [7]. As the debate progressed, it became clear that most people accepted that animal use was justified providing there was a clear, and important, benefit from the animal experiments and, very importantly indeed, that the animals did not suffer. The debate about what constitutes suffering continues - some people feel that caging animals constitutes suffering whereas others have a much higher threshold.

The next key question is what is an acceptable benefit of an animal experiment? There was almost unanimous agreement that the benefit of a new cosmetic does not justify animal testing. The thinking behind this was that cosmetics are for personal adornment and have a peculiarly personal benefit; thus the risk should be borne by their users. Within a decade the European Commission developed legislation that prohibited the use of animals to test cosmetics [8]. Toxicologists and antivivisectionists alike were content with this outcome.

There will always be disagreement about animal use in experiments, but the legislation preventing animal use in cosmetics testing was an important milestone in uniting opinions of two opposing factions. This debate is important to keep scientists who use animals in their work aware of the value of the lives of the animals they use and the importance of keeping suffering to an absolute minimum.

Antivivisectionists provided an important driver for scientists to develop new methodology to replace animals, particularly for pharmaceuticals' testing. Indeed toxicologists have long had the mantra, 'RRR - reduce, refine, replace' [9] which refers to using fewer animals, reducing suffering or, ideally, replacing animals with alternative testing methods. Nowadays, a good proportion of safety assessment methods involve ex vivo systems in which a single animal is killed to provide the material for multiple tests; cell culture systems that negate the use of live animals; structure activity relationships (SARs) that consider molecular analogies responsible for toxicological traits; and in vitro methods that explore the interaction between test molecules and simulated biological systems. Despite all of these methods which very significantly reduce animal use, there is still the need to carry out animal tests as part of risk assessments to be sure that the whole animal responds to a new pharmaceutical in the way predicted by in vitro, ex vivo and SARs studies. Most toxicologists are comfortable with this need to use animals and accept that this is unlikely to change. This, in combination with strict ethical guidelines enforced by Animal Ethics Committees, ensures the appropriate and humane use of animals.
To require recreational drugs to be subjected to ostensibly the same testing (except for some chronic toxicity evaluations - arguably the most important human toxicological outcome of recreational drug use [10]) as pharmaceuticals flies in the face of the decades of argument and debate that led to the current approach to animal use in pharmaceutical risk assessment. It requires a drug with no societal or arguably personal benefit to be subjected to animal testing. Most toxicologists, I think, would object to this. If such testing requirements are made mandatory, this will put toxicologists in a very difficult position and rekindle the argument about the ethics of animal use in drug testing. This would be a very great pity indeed - it would betray some very good relationships and agreements between opposing parties that have developed over the past 4 decades.

So what could be done to assess the safety of recreational drugs if they are to become legal entities? We could utilise a battery of in vitro, cell culture, ex vivo and SAR studies as risk indicators. From such studies definitively unacceptable risks will be obvious (e.g. high acute toxicity), but more esoteric toxic effects (e.g. long term psychological effects) are unlikely to be shown. Using such a risk assessment regime, a proportion of the risk burden would be taken by the consumer in the same way as consumers of tobacco or alcohol accept the risk associated with their enjoyment of these products. And, in the same way that tobacco and alcohol products are labelled to make their consumers aware of the risks associated with their use, recreational drugs could be labelled to make it clear that they have not been fully risk assessed and that there are likely to be risks associated with their use (and they could be listed). This will direct the burden of risk on to the consumer who receives the benefit. In addition, this approach might deter potential consumers from using recreational drugs which will inevitably have long term negative societal consequences.

It might, of course, be more sensible not to try to regulate the unregulatable, but that is a very different argument...

Acknowledgements I thank Professor Tony Fox for his insightful and very helpful comments.

Conflict of interest This work received no external funding and the author has no conflicts of interest.

\section{References}

1. Rudgley R. The alchemy of culture-intoxicants in society. London: British Museum Press; 1993. p. 24-7.

2. Foxcroft L. The making of addiction: the 'use and abuse' of opium in nineteenth-century Britain. Aldershot: Ashgate Publishing Ltd; 2007. p. 57. 
3. Townsend P. Who I am. Harper Collins, London; 2012.

4. Consroe P, Mustry R, Tillery W, Pertwee R. The perceived effects of smoked cannabis on patients with multiple sclerosis. Eur. Neurol. 1997;38(1):44-8.

5. The All American Cannabis Club. Compassionate Use Act of 1996 (Prop 215). http://a2c2.us/the-laws/compassionate-use-actof-1996-prop-215/. Accessed 12 June 2013.

6. New Zealand Government. Psychoactive Substances Bill 100-1. http://www.legislation.govt.nz/bill/government/2013/0100/latest/ versions.aspx. Accessed 4 June 2013.

7. Paton W. Man and mouse-animals in medical research. Oxford: Oxford University Press; 1984.
8. European Commission. Communication from the Commission to the European Parliament and the Council on the animal testing and marketing ban and on the state of play in relation to alternative methods in the field of cosmetics. http://ec.europa.eu/ consumers/sectors/cosmetics/files/pdf/animal_testing/com_at_ 2013_en.pdf. Accessed 4 June 2013.

9. Russell WMS, Burch RL. The principles of humane experimental techniques. London: Methuen; 1959.

10. Pierre JM Cannabis, synthetic cannabinoids, and psychosis risk: what the evidence says. Curr Psychiatry. 2011; 10(9): 49-58. 